\title{
DISEMINASI BAK PENGOLAHAN LIMBAH CAIR DENGAN ELEKTROKOAGULASI DAN FILTRASI PADA USAHA SARUNG TENUN ATBM DI KECAMATAN CERME KABUPATEN GRESIK BERBASIS GREEN PRODUCTION
}

\author{
Andi Iswoyo ${ }^{1}$, Ong Andre Wahyu Riyanto², Muhammad Muchid², Yanuar Fauzuddin ${ }^{1}$, Hendrik \\ Rizqiawan $^{1}$ \\ ${ }^{1}$ Fakultas Ekonomi dan Bisnis, Universitas Wijaya Putra \\ ${ }^{2}$ Fakultas Teknik, Universitas Wijaya Putra
}

andi@uwp.ac.id, ongandre@uwp.ac.id, muhammadmuchid@uwp.ac.id, yanuarfauzuddin@uwp.ac.id, hendrikrizqiawan@uwp.ac.id

\begin{abstract}
Abstrak
Program ini dilaksanakan berdasarkan hasil pengamatan terhadap salah satu permasalahan yang dihadapi mitra, hasil sampingan berupa limbah buangan (waste) berupa limbah cair yang dihasilkan dari proses pencelupan/pewarnaan benang dan pencucian sarung yang belum dikelola dengan baik oleh Mitra, karena keterbatasan pengetahuan dan biaya. Tujuan dari program ini adalah mitra memahami pentingnya berwirausaha dengan tetap memperhatikan kelestraian lingkungan dan bersedia untuk mengolah limbahnya agar tidak mencemari lingkungan. Solusi yang diberikan yaitu dengan membuat bak pengolahan limbah cair dengan elektokoagulasi dan filtrasi. Metode palaksanaannya yaitu perencanaan dan diseminasi bak pengolah limbah, pelatihan pengoperasian dan maintenance bak pengolah limbah dan pendampingan pengoperasian. Hasil pelaksanaan program ini diantaranya diseminasi bak pengolahan limbah dengan elektrokoagulasi dan filtrasi dengan kapasitas hingga 150-liter perhari, pelatihan dan pendampingan pengoperasioan bak pengolah limbah pada pengusaha dan operator pencelupan pewarna, serta operator sudah mampu maintenance bak pengolahan limbah dengan baik. Bak pengolah limbah dengan elektrokoagulasi dan filtrasi ini mampu menurunkan kadar BOD, COD dan TSS pada limbah mendekati baku mutu, sehingga aman bagi lingkungan.
\end{abstract}

Kata Kunci : elektrokoagulasi, filtrasi, limbah cair, sarung tenun

\section{PENDAHULUAN}

Kabupaten Gresik memiliki julukan sebagai kota santri sekaligus kota industri, hal ini tidak berlebihan dikarenakan kabupaten ini mampu menggabungkan antara religiusitas dan industri dengan sangat baik. Hal ini dapat dilihat dengan banyaknya industri besar dan kecil di kota ini. Salah satu hal yang sudah mengakar kuat adalah adanya usaha sarung tenun ATBM (Alat Tenun Bukan Mesin) dan Songkok yang merupakan ciri khas budaya santri.

Salah satu bukti nyata Kabupaten Gresik sebagai kota industry adalah, 49,59 persen dari total nilai nilai PDRB Kabupaten Gresik, disumbang darisektor industri pengolahan. Nilai investasi di Kabupaten Gresik juga terus mengalami peningkatan dari tahun ke tahun, baik itu 
Penanaman Modal Asing maupun Penanaman Modal Dalam Negeri. Pada tahun 2019, nilai investasi Penanaman Modal Dalam Negeri di Kabupaten Gresik sebesar 3,2 triliun rupiah dan meningkat menjadi 12,3 triliun rupiah pada tahun 2020 (BPS Kabupaten Gresik, 2021).

Salah satu industri kecil dan menengah yang banyak di Kabupaten Gresik adalah industri sarung tenun ATBM (alat tenun bukan mesin) tersebar di berbagai kecamatan, diantaranya di Kecamatan Gresik, Kecamatan Kebomas, Kecamatan Cerme dan Kecamatan Benjeng. Di dua kecamatan terakhir tersebut bahkan jumlahnya mencapai ratusan industri yang tersebar di beberapa desa. Diantaranya yang menjadi sentra adalah di Desa Ngembung, Desa Wedani dan Desa Semampir Kecamatan Cerme serta Desa Jogodalu dan Desa Klampok Kecamatan Benjeng. Tidak salah jika kemudian Kabupaten Gresik, dinyatakan sebagai satu-satunya sentra industri sarung alat tenun bukan mesin (ATBM) di Indonesia. Hal ini sesuai dengan surat penetapan dari Menteri Perindustrian No. 95/M-IND/PER/10/2014 tentang Peta Panduan Pengembangan Kompetensi Inti Industri Kabupaten Gresik, bahwa Gresik sebagai sentra sarung tenun ATBM

Sarung Tenun ATBM memang terbilang unik karena proses pengerjaannya masih tradisional dan cukup rumit dan panjang serta butuh modal yang cukup besar. Meskipun begitu, produksi sarung ATBM ini sudah menembus pasar ekspor diantaranya ke Brunei Darusalam, Malaysia, Philipina, bahkan negara-negara timur tengah diantaranya Arab Saudi dan Uni Emirat Arab.

Salah satu kendala yang dihadapi hamper seluruh pengusaha sarung tenun tradisional di Kabupaten Gresik adalah hasil sampingan berupa limbah cair dari proses pewarnaan benang yang cukup banyak, berwarna pekat dan mencemari lingkungan. Rata-rata limbah yang dihasilkan oleh satu pengusaha sebanyak 100-200 liter. Jumlah ini sangat tergantung pada besar kecilnya jumlah produksi sarung. Pada umumnya mereka langsung membuang limbah tersebut ke sungai atau saluran air, dan jika pada musim hujan akan terbawa dan mencemari sungai atau perairan lainnya.

Limbah tenun ini merupakan limbah yang didominasi air sebagai media pelarut sehingga dikategorikan limbah cair yang dihasilkan dari proses pewarnaan dan juga pencucian dengan bahan kimia tertentu. Limbah ini sebabkan penggunaan senyawa kimia sintesis yang sangat mencemari lingkungan. Zat pewarna ini mudah diserap oleh serat benang sehingga cukup efektif sebagai pewarna dan tidak luntur. Dalam proses pencelupan warna, digunakan alkali untuk proses fixsasi warna, sehingga $\mathrm{pH}$ air menjadi tinggi. Warna limbah sarung tenun cenderung pekat, hal ini dikarenakan tidak semua zat kimia pewarna digunakan dapat berdiksasi dengan serat benang, sedangkan kadar COD yang sangat tinggi disebabkan oleh adanya zat-zat organik yang terkandung didalamnya seperti zat pembasah, zat warna dan zatpembantu lainnya (Rahayu \& Aulia, 2015).

Hasil laboratorium pada limbah cair sarung tenun lainnya adalah parameter suhu, $\mathrm{pH}$, TSS, BOD, COD, ammonia dan sulfat melebihi baku mutu sedangkan parameter fenol belum melampaui baku mutu jika dibandingkan dengan Perda Jawa Tengah No.10/2004 (Rahmawati \& Suratman, 2010). Berdasarkan data tersebut, limbah cair yang masuk kedalam area sungai, saluran air dan atau persawahan, dapat dikategorikan dalam pencemaran sedang dan tinggi.

Berdasarkan Peraturan Kementerian Lingkungan Hidup dan Kehutanan Tahun 2016, baku mutu air limbah domestik ditetapkan berdasarkan tingkat $\mathrm{pH}, \mathrm{BOD}, \mathrm{COD}$, TSS, Minyak \& Lemak, Amoniak, Total Coliform dan Debit. Adapun baku mutu masing-masing parameter, sebagai berikut:

Tabel 1 Baku Mutu Air Limbah Domestik Tersendiri

\begin{tabular}{lcc}
\hline \multicolumn{1}{c}{ Parameter } & Satuan & Kadar Maksimum \\
\hline $\mathrm{pH}$ & - & $6-9$ \\
\hline $\mathrm{BOD}$ & $\mathrm{mg} / \mathrm{L}$ & 30 \\
\hline $\mathrm{COD}$ & $\mathrm{mg} / \mathrm{L}$ & 100 \\
\hline $\mathrm{TSS}$ & $\mathrm{mg} / \mathrm{L}$ & 30 \\
\hline Minyak \& lemak & $\mathrm{mg} / \mathrm{L}$ & 5 \\
\hline Amoniak & $\mathrm{mg} / \mathrm{L}$ & 10 \\
\hline Total Coliform & jumlah/100mL & 3000 \\
\hline Debit & L/orang/hari & 100 \\
\hline
\end{tabular}


Sumber: Permen LHK No. 68 Th 2016, 2016

Beberapa metode banyak dilakukan oleh peneliti guna menurunkan kadar BOD, COD dan TSS pada limbah sarung tenun ini. Said (2008) meneliti tentang pengolahan limbah sarung songket dengan menggunakan metoda filtrasi dan adsorbsi. Metode ini menggunakan metode filtrasi guna mendapatkan komposisi dan ukuran yang tepat bagu alat penyaring sederhana dan mendapatkan kondisi perasi yang tepat bagi kolom adsorbsi. Metode ini cukup efektif menurunkan kadar COD dan TSS limbah hingga 99\% pada limbah warna hijau dan $50 \%$ pada limbah warna ungu, namun untuk kondisi limbah yang besar, metode ini kurang efektif, dan membutuhkan filter dan koagulen yang banyak.

Metode lainnya adalah dengan menggunakan kitosan. Kitosan merupakan ekstrak kulit binatang berkulit keras seperti udang dan kepiting. Sumber kitosan sangat melimpah di alam terutama dari hewan golongan krustase seperti udang dan kepiting (Pratiwi, 2014). Hasil penelitan (Rahayu \& Aulia, 2015) menunjukkan bahwa peran kitosan ini mampu menurunkan TSS $88,79 \%$ dan warna $35,49 \%$ namun menurunkan kadar $\mathrm{pH}$ menjadi 4,98 yang disebabkan oleh penggunaan asam asetat sebagai pelarut kitosan.

Salah satu metode yang paling popular digunakan untuk mengolah limbah cair sarung tenun adalah dengan metode elektrokogulasi. Metode ini menggabungkan proses elektrokimia dan proses flokulasi-koagulasi (Djajadiningrat, 2004).

Elektrokoagulasi merupakan proses koagulasi yang kompleks dan kontinyu dengan menggunakan arus listrik searah melalui proses elektrokimia. Pada kuutb anoda dengan metode ini terjadi pelepasan koagulen aktif berupa ion logam ke dalam larutan, sedangkan pada sisi lainnya, katoda, terjadi reaksi elektrolisis berupa pelepasan gas hydrogen. (Holt et al., 2002). Metode ini juga mampu menyisikan berbagai polutan dalam limbah cair, antara lain partikel tersuspensi, logam berat, zat pewarna, dan lain-lain (Wahyulis et al., 2014). Kelebihan dari metose ini adalah tidak menggunakan mzak kimia, namun memiliki efektifitas yang tinggi, efisien dari sisi biaya karena dapat menggunakan bahan yag sederhana dan mudah didapat.

Gambar 1. Interaksi yang terjadi dalam reaktor

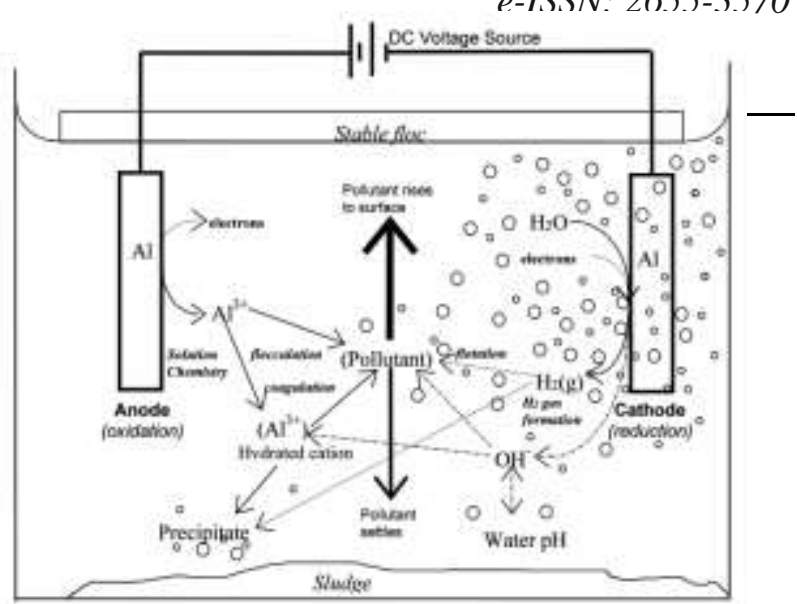

elektrokoagulasi (Holt et al., 2002)

Metode elektrokoagulasi juga dapat diterapkan pada pengolahan limbah sarung tenun. Penelitian oleh Melani et al., (2017) memberikan data bahwa limbah sarung tenun dapat diproses dan terbukti mampu menurunkan $\mathrm{pH}$ hingga 20,73\% dan penurunan COD hingga 33,01\% dalam waktu 60 menit. Selain itu, metode elektrokoagulasi juga mampu menurunkan kadar TSS hingga 54,45\% dalam waktu 60 menit.

Berdasarkan penelitian-penelitian diatas, guna membantu pengusaha sarung tenun di Kabupaten Gresik, utamanya pada mitra sasaran di Desa Semampir Kecamatan Cerme Kabupaten Gresik, perlu dibuatkan reactor elektrokoagulasi untuk menangani limbah yang dihasilkan dari produksi sarung tenun.

\section{METODE}

Langkah-langkah dalam pelaksanaan program ini adalah 1). Identifikasi Kebutuhan Mitra Sasaran, melalui pengamatan dan wawancara, terkait kapasitas limbah cair harian, komposisi limbah, kesediaan mitra menanggung biaya yang timbul, ketersediaan lahan untuk IPAL, dan kesediaan tenaga kerja mengoperasikan IPAL; 2) Perancangan ulang desain IPAL; 3). Pembuatan Bak Pengolah Limbah dengan proses pengadaan bahan, ppname pembuatan bak IPAL; 4) Perakitan dan uji operasi. dilakukan secara langsung terhadap limbah cair yang dihasilkan mitra, kemudian diukur tingkat efektifitasnya melalui hasil uji laboratorium terhadap kandungan kimia sebelum dan sesudah pengolahan; 5). Pendampingan Operasional, guna memastikan bak IPAL berfungsi sempurna dan mitra dapat menggunakannya dengan baik, serta 6). 
Penerapan bak IPAL yang telah diserahkan kepada mitra sasaran.

\section{HASIL DAN PEMBAHASAN}

\section{Identifikasi Kebutuhan Mitra}

Pada tahapan ini, dilakukan identiifkasi kondisi limbah yang dihasilkan oleh mitra. Kapasitas limbah yang dihasilkan oleh mitra sebesar 100-200liter per hari. Mitra bersedia menyediakan lahan berukuran $4 \times 2 \mathrm{mtr}$ guna tempat pengolahan limbah

\section{Perancangan ulang desain IPAL}

Perancangan ini dilakukan pada desain yang sudah dimiliki guna menyesuaikan dengan kapasitas limbah yang lebih kecil dari desain tim pelaksana serta menyesuaikan lokasi yang dimiliki mitra tempat bak IPAL Hasil perancangan ulang ini terdiri dari 1 bak penampungan kapasitas 400 liter, 1 bak elektrokoagulasi kapasitas 150 liter, 1 bak pengendapan kapasitas 216 liter dan 3 bak filtrasi masing-masing berkapasitas 150 liter.

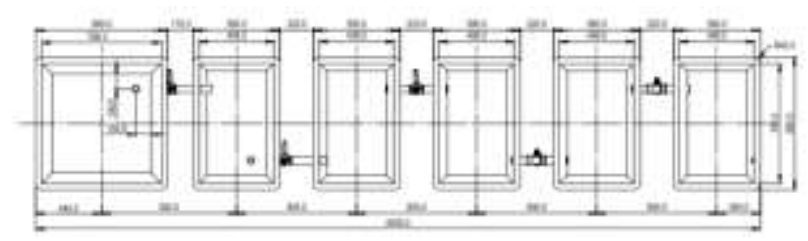

Gambar 2. Rancangan bak IPAL

\section{Pembuatan bak IPAL}

Pembuatan bak IPAL dilakukan oleh vendor di Gresik. Bahan yang dipilih untuk pembuatan bak IPAL adalah stainless steel 304. Bahan ini dipilih karena air limbah yang bersifat korosif sehingga perlu bahan yang kuat, awet dan mudah dalam proses pembuatannya.

Sedangkan untuk menyambungkan antar bak digunakan pipa stainless steel dia. 1 inchi, ballvalce 1 inchi, watermur, dan lain-lain. Proses pembuatan bak IPAL ini, antara lain; Pemilihan bahan, pemotongan, penekukan, pengelasan, pengamplasan dan finishing/poles. Setelah semua bahan siap, tahap berikutnya adalah merangkai/assembly.
Untuk bak penampungan dan bak elektrokoagulasi digunakan pangkon dari siku besi dengan ketinggian $20 \mathrm{~cm}$ dan $60 \mathrm{~cm}$. hal ini dilakukan agar ada tekanan untuk mengalirnya air limbah. Pada reaktor elektrokoagulasi digunakan

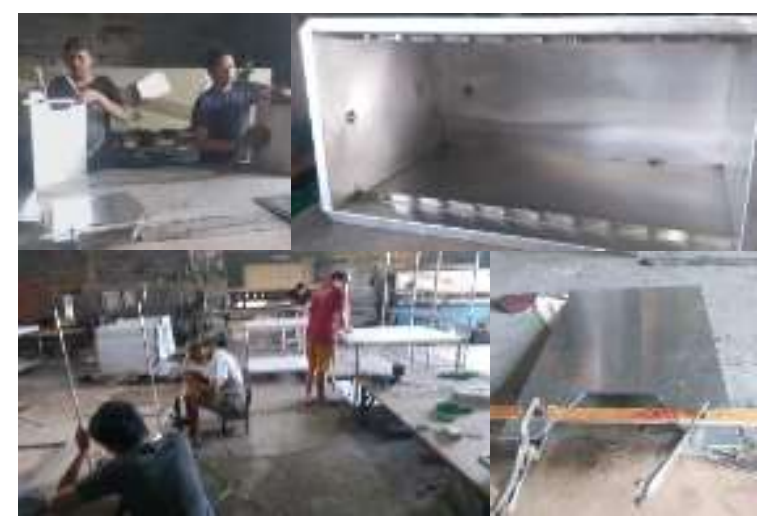

plat aluminium ukuran 400x500x1mm sebagai anoda dan katoda sejumlah 5 pasang.

Gambar 3. Pembuatan bak IPAL

\section{Perakitan dan Uji Operasi}

Bak IPAL yang didiseminasikan telah diuji operasi beberapa kali, hal ini untuk menemukan tegangan/volt, arus/amphere dan daya/watt yang tepat sehingga proses elektrokoagulasi dapat cepat/efektif memisahkan konsentrasi limbah pewarna dan murah/efisien terkait daya yang dibutuhkan.

Proses uji operasi bak IPAL ini dimulai dari penampungan limbah cair yang semula langsung dibuang oleh operator, saat ini harus dimasukkan kedalam bak penampung. Dari bak penampung, limbah cair dipompa ke bak elektrokoagulasi, di sini, limbah cair diberikan arus listrik DC dengan besaran 20A dan 9V. Dengan arus dan tegangan sebesar itu, sudah menghasilkan reaksi pada limbah cair, dimana pada menit pertama proses elektrokoagulasi sudah menghasilkan flok (gumpalan) yang merupakan limbah dengan konsentrasi dan warna yang lebih pekat, hal ini menandakan bahwa proses elektrokoagulasi sudah berhasil memisahkan komposisi pewarna dengan air.

Pada proses ini, pelaksana mencari durasi elektrokolagulasi yang paling optimal guna 
menghasilkan olahan limbah yang paling efektif dan efisien, dan hasil tersebut kemudian diujikan pada laboratorium Teknik lingkungan ITS.

Proses berikutnya setelah proses elektrokoagulasi, air limbah dialirkan ke bak pengendapan untuk diendapkan selama 2 hari, ini berfungsi untuk memisahkan flok dengan air. Dari bak pengendapan ini, air limbah masih berwarna sehingga harus dialirkan ke bak filtrasi yang terdiri dari bak pertama berisi ijuk, bak kedua berisi batu apung dan bak ketiga arang batok kelapa. Dengan mekanisme gravitasi, proses filtrasi ini menghasilkan luaran air yang lebih jernih dan secara visual tidak ada lagi konsentrasi limbah pewarna.

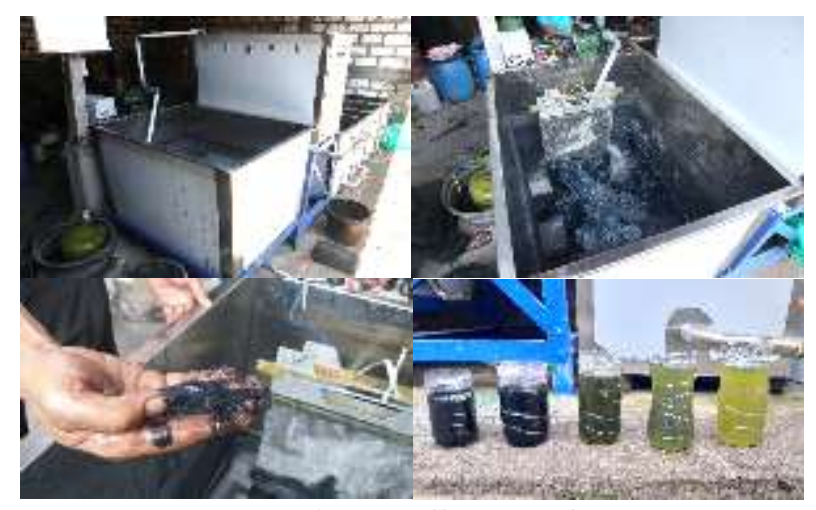

Gambar 4 Uji Operasi

Hasil uji limbah operasi pada gambar di atas, merupakan hasil pengamatan secara visual, untuk mengukur tingkat keberhasilan keseluruhan proses ini, saat ini limbah sedang diuji di laboratorium Teknik Lingkungan Institut Teknologi Sepuluh Nopember (ITS). Uji laboratorium ini untuk mengukur kadar Biological Oxygen Demand (BOD), Chemical Oxygen Demand (COD), and Total Suspended Solid (TSS).

Tabel 2 Hasil Uji Laboratorium

\begin{tabular}{cccc}
\hline Parameter & Satuan & $\begin{array}{c}\text { Sebelum } \\
\text { Proses }\end{array}$ & $\begin{array}{c}\text { Setelah } \\
\text { Proses }\end{array}$ \\
\hline $\mathrm{pH}$ & - & 8,7 & 6,5 \\
\hline $\mathrm{BOD}$ & $\mathrm{mg} / \mathrm{L}$ & 932 & 121 \\
\hline $\mathrm{COD}$ & $\mathrm{mg} / \mathrm{L}$ & 963 & 143 \\
\hline $\mathrm{TSS}$ & $\mathrm{mg} / \mathrm{L}$ & 1033 & 116 \\
\hline
\end{tabular}

BOD merupakan parameter pengukuran jumlah oksigen yang dibutuhkan oleh bekteri untuk mengurai hampir semua zat organik yang terlarut dan tersuspensi dalam air buangan, dinyatakan dengan BOD5 hari pada suhu $20{ }^{\circ} \mathrm{C}$ dalam mg/liter atau ppm, sedangkan COD adalah jumlah oksigen yang dibutuhkan untuk mengoksidasi zat-zat organik yang terdapat dalam limbah cair dengan memanfaatkan oksidator kalium dikromat sebagai sumber oksigen dan TSS merupakan zat yang tersuspensi biasanya terdiri dari zat organik dan anorganik yang melayang-layang dalam air, secara fisika zat ini sebagai penyebab kekeruhan pada air. Limbah cair yang mempunyai kandungan zat tersuspensi tinggi tidak boleh dibuang langsung ke badan air karena disamping dapat menyebabkan pendangkalan juga dapat menghalangi sinar matahari masuk kedalam dasar air sehingga proses fotosintesa mikro-organisme tidak dapat berlangsung (Atima, 2015).

Pada tabel 2 diatas, dapat dilihat bahwa proses ini memiliki efektifitas dan efisiensi yang cukup baik meskipun belum mampu menurunkan kadar BOD, COD dan TSS sesuai dengan baku mutu yang ditetapkan Kementerian LHK. Kadar BOD sebagaimana baku butu KLHK adalah sebesar $30 \mathrm{mg} / \mathrm{L}$, hasil uji operasi ini menghasilkan $\mathrm{pH}$ 6,5, BOD sebesar $121 \mathrm{mg} / \mathrm{L}$, COD sebesar $963 \mathrm{mg} / \mathrm{L}$ dan TSS sebesar $116 \mathrm{mg} / \mathrm{L}$. Angka ini sudah cukup besar karena mampu menurunkan kadar BOD sebesar $87 \%$. Sedangkan pada COD, mampu menurunkan hingga $85 \%$ dan TSS hingga $89 \%$.

\section{Pendampingan Operasional}

Pada tahapan ini, mitra diberikan pelatihan pengoperasian bak IPAL terutama pada elektokoagulasi, penggunaan powersupply dan filtrasi. Operator bak IPAL ini juga diajarkan penggunaan Alat Pelindung Diri (APD) berupa pemakaian katelpak, celemek/apron, sepatu boot dan sarung tangan karet selama proses pencelupan warna hingga pengoperasioan bak IPAL.

\section{Penerapan bak IPAL yang telah diserahkan kepada mitra sasaran}

Pada tahapan ini, bak IPAL yang sudah berfungsi dengan baik diserahkan kepada mitra melalui penandatanganan berita acara serah terima barang beserta panduan pengoperasian dan 
maintenance alat.

\section{KESIMPULAN}

Diseminasi bak IPAL dengan elektrokoagulasi dan filtrasi yang diberikan kepada mitra sudah berfungsi dengan baik. Penurunan kadar $\mathrm{pH}$ limbah sudah didalam baku mutu yaitu 6,7 , sedangkan pada parameter BOD, COD dan TSS penurunannya mencapai $85-89 \%$. Meskipun masih diatas baku mutu, namun pengolahan limbah ini sudah cukup aman bagi lingkungan dan tidak lagi berwarna pekat.

Saran pada pelaksanaan pengabdian kepada masyarakat sejenis berikutnya agar memperhatikan kapasitas limbah yang akan diolah, kandungan zat kimia dan efektifitas dari biaya pengoperasian bak IPAL tersebut.

\section{UCAPAN TERIMAKASIH}

Ucapan terimakasih disampaikan kepada Badan Riset dan Inovasi Nasional (BRIN) yang telah memberikan pendanaan melalui Program Produk Teknologi yang Didiseminasikan ke Masyarakat (PTDM) pendanaan tahun 2021, serta Rektorat dan LPPM Universitas Wijaya Putra atas ijinnya mengunakan teknologi yang dimiliki untuk didiseminasikan ke masyarakat.

\section{REFERENSI}

Atima, W. (2015). BOD DAN COD SEBAGAI PARAMETER PENCEMARAN AIR DAN BAKU MUTU AIR LIMBAH. Jurnal Biology Science \& Education, 4(1), 88-98. https://core.ac.uk/download/pdf/229361024.pd $\mathrm{f}$

BPS Kabupaten Gresik. (2021). Kabupaten Gresik Dalam Angka 2021. In Badan Pusat Statistik Kabupaten Gresik.

Djajadiningrat, A. H. (2004). Pengolahan Limbah Cair Tanpa Bahan Kimia. Institut Teknologi Bandung.

Holt, P. K., Barton, G. W., Wark, M., \& Mitchell, C. A. (2002). A Quantitative Comparison Between Chemical Dosing and Electrocoagulation. Colloids and Surfaces A:
Physicochemical and Engineering Aspects, 211(2-3), 233-248. https://doi.org/10.1016/S0927-

7757(02)00285-6

Permen LHK No. 68 th 2016, 68 Kementerian Lingkungan Hidup dan Kehutanan 1 (2016). http://neo.kemenperin.go.id/files/hukum/19 Permen LHK th 2016 No. P.63 Baku Mutu Air Limbah Domestik.pdf

Melani, A., Andre, \& Rifdah. (2017). Kajian Pengaruh Waktu dan Ukuran Lempengan Terhadap Limbah Cair Industri Kain Tenun Songket Dengan Metode Elektrokoagulasi. Distilasi, 2(1), 23-34.

Pratiwi, R. (2014). Manfaat kitin dan kitosan bagi kehidupan manusia. Oseana, 39(1), 35-43.

Rahayu, D. E., \& Aulia, S. (2015). Penurunan Warna dan TSS Limbah Cair Tenun Sarung Samarinda Menggunakan Kitosan Dari Limbah Cangkang Kepiting. Jurnal Purifikasi, 15(1), 1-11. https://doi.org/10.12962/j25983806.v15.i1.20

Rahmawati, N. A., \& Suratman. (2010). Pengaruh Limbah Cair Industri Sarung Tenun pada Air Irigasi dan Pengaruhnya terhadap Produksi Padi dan Kualitas Lingkungan (Studi Kasus di Desa Wanarejan Kabupaten Pemalang Jawa Tengah).

http://etd.repository.ugm.ac.id/home/detail_pe ncarian/46468

Said, M. (2008). Pengolahan Limbah Cair Hasil Pencelupan Benang Songket Dengan Metoda Filtrasi dan Adsorpsi. In Jurnal Penelitian Sains (Vol. 11, Issue 2, pp. 474-480).

Wahyulis, N. C., Ulfin, I., \& Harmami. (2014). Optimasi Tegangan pada Proses Elektrokoagulasi Penurunan Kadar Kromium dari Filtrat Hasil Hidrolisis Limbah Padat Penyamakan Kulit. Jurnal Sains Dan Seni Pomits, 3(2), 9-11. 